\title{
Long-term variation of the Antarctic Circumpolar Wave
}

\author{
W. M. Connolley \\ British Antarctic Survey, Cambridge, UK \\ Received 10 April 2000; revised 31 May 2001; accepted 10 September 2001; published XX Month 2002.
}

[1] During the period 1968-1999, the character of circum-Antarctic anomalies in sea level pressure, sea ice edge, and sea surface temperature changed substantially. An Antarctic Circumpolar Wave (ACW) is only clearly visible in the period 1985-1994. Before, and perhaps after this, the signal, particularly in sea level pressure, is quite different with no clear sign of precession. Accompanying the change from precessional to nonprecessional modes is a change in the spatial pattern of variability and a change in the predictability of atmospheric anomalies from oceanic forcing. Evidence from general circulation model integration suggests that during the precessional mode of the ACW, there is enhanced predictability, as would be required to support a coupled oceanatmosphere interaction. INDEX TERMS: 4207 Oceanography: General: Arctic and Antarctic oceanography; 4215 Oceanography: General: Climate and interannual variability (3309); 4255 Oceanography: General: Numerical modeling; 3339 Meteorology and Atmospheric Dynamics: Ocean/atmosphere interactions (0312, 4504); KEYWORDS: Antarctic Circumpolar Wave (ACW), Antarctic, Climate variability, General circulation model (GCM)

Citation: Connolley, W. M., Long-term variation of the Antarctic Circumpolar Wave, J. Geophys. Res., 107(0), XXXX, doi:10.1029/ 2000JC000380, 2002.

\section{Introduction}

[2] An apparent 8 year periodicity in the length of the sea ice season at Signy station in the South Orkney Islands was noted by Murphy et al. [1995] and linked to an eastward precession of anomalies in sea ice edge. However, they noted that the periodicity was only seen between the middle 1960s and 1990. We reanalyze this record below and show that it is indeed dominated by 8 year periodicity but shows a 4 year period after 1985. White and Peterson [1996] (hereinafter referred to as WP) proposed that these anomalies in sea ice edge (SIE) were part of an Antarctic Circumpolar Wave $(\mathrm{ACW})$ in sea ice, atmospheric pressure (mean sea level pressure (MSLP)), sea surface temperature (SST), and wind stress. The ACW as revealed by their analysis has a wave number of 2 and takes $8-10$ years to circle Antarctica, leading to a periodicity of $4-5$ years at any location. WP did not detail the mechanism for this wave but proposed that its initiation was connected to El Niño-Southern Oscillation (ENSO) forcing in the South Pacific. Jacobs and Mitchell [1996] observed propagating anomalies in SST, sea surface height, and wind stress curl, which were compatible with the ACW of WP. Qiu and Jin [1997] proposed a mechanism for the ACW based on local ocean-atmosphere interaction. White et al. [1998] proposed a detailed mechanism for the ACW as a fully coupled ocean-atmosphere mode, which they tested on a simplified, permanent winter model. Christoph et al. [1998] found something similar to the ACW in the Max Planck Institute European Center/Hamburg (ECHAM)/OPYC coupled atmosphere-ocean general cir-

Copyright 2002 by the American Geophysical Union. 0148-0227/02/2000JC000380\$09.00 culation model (AOGCM), though they noted that the model "wave" had a wave number of 3 rather than 2, that it did not always appear to be circumpolar, and that the MSLP component often had the characteristic of a standing pattern rather than a precessing wave. Cai et al. [1999] interpreted results from the Commonwealth Scientific and Industrial Research Organisation AOGCM as showing a standing MSLP oscillation and a travelling SST signal, again with a wave number of 3. Bonekamp et al. [1999] studied the ACW using European Centre for MediumRange Weather Forecasts (ECMWF) reanalyses and an ocean model forced by these reanalyses. From the reanalyses they concluded that the ACW signal was only present in MSLP during the period 1985-1994. From forcing experiments with a geostrophic ocean model they found that oceanic anomalies with an ACW-like signature could be generated by a one-way atmosphere to ocean forcing. Weisse et al. [1999] forced the same ocean model with spatially realistic and temporally random atmospheric forcing and generated a variety of ACW-like oceanic anomalies, depending upon the pattern of forcing imposed.

[3] However, all the modeling experiments conducted are made difficult to interpret by deficiencies in the models, generally an Antarctic Circumpolar Current (ACC) that is too slow. Christoph et al. [1998] noted that although their coupled AOGCM usually produced a wave number 3 pattern, in about $20 \%$ of cases the wave number was 2 , and in these cases the SST anomalies were advected faster, in better agreement with WP. White et al. [1998] found that in the absence of ocean-atmosphere coupling, in a simplified model the anomalies advected slowly and soon dissipated; whereas with coupling the anomalies advected at the observed speed. Thus if the ACC speed is wrong, the 

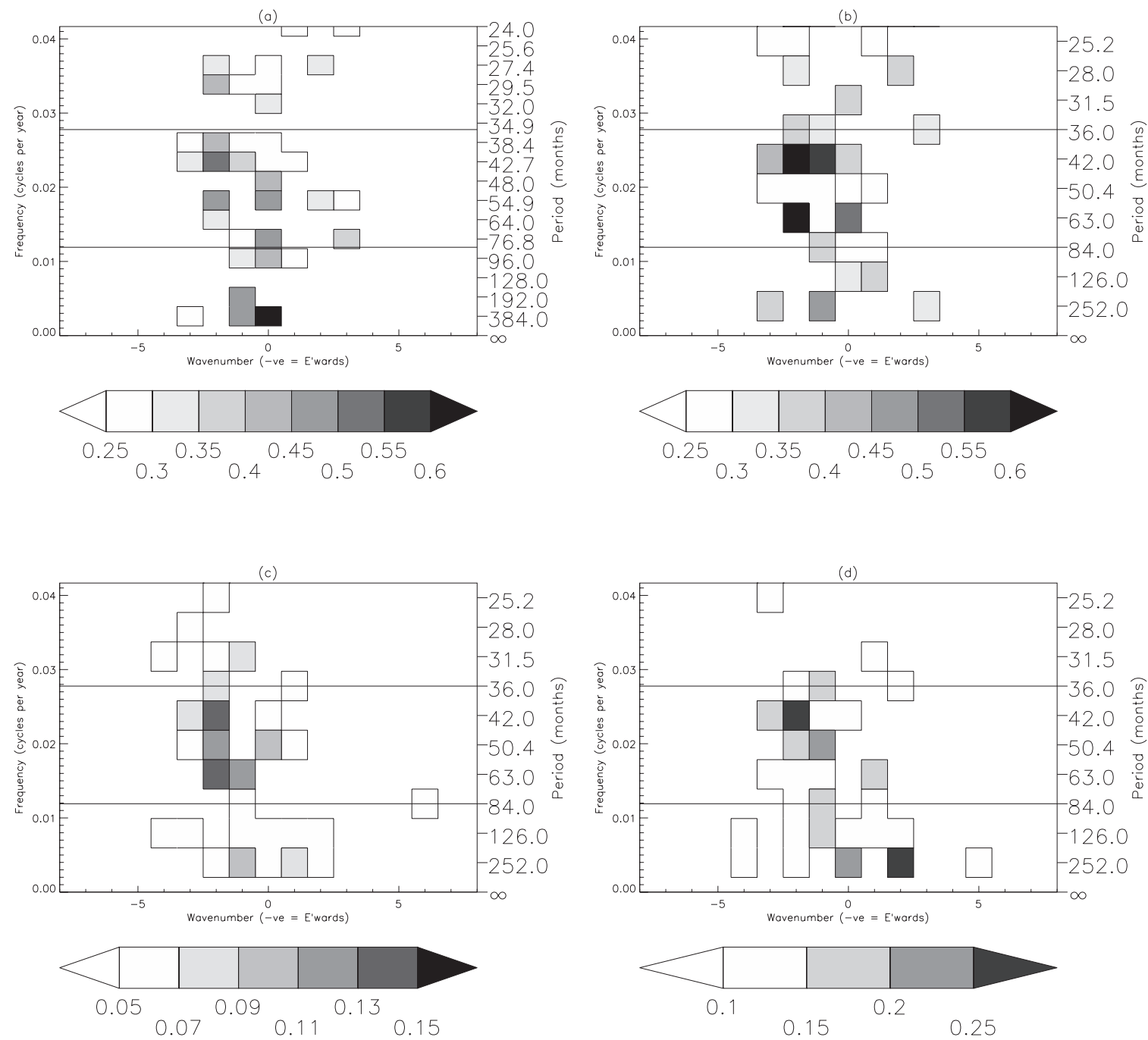

(a) MSLP (NCEP)
(b) MSLP (ECMWF)
(c) SST
(d) SIE

Figure 1. Amplitude of wave number-frequency spectra of Hovmöller plots of anomalies along $56^{\circ} \mathrm{S}$ in (a) NCEP MSLP (hPa), (b) ECMWF MSLP (hPa), (c) ECMWF SST ( $\left.{ }^{\circ} \mathrm{C}\right)$, and (d) anomalies of SIE (degrees latitude). Horizontal lines show the periods ( 3 and 7 years) at which the data are filtered to construct Figure 2. Left-hand scale: frequency; right-hand scale: period.

critical coupling between ocean and atmosphere may be wrong, and the models may produce misleading results.

[4] In this paper we show that during the period $1968-$ 1999 the character of the SST and MSLP anomalies as seen in the ECMWF and National Centers for Environmental Prediction (NCEP) reanalysis have changed substantially, either because it is intrinsically variable or because of "external" forcing, perhaps ENSO. The ACW is only clearly visible in the period 1985-1994, which is, fortuitously, the period used in the WP analysis. Before and perhaps after this, the signal (particularly in MSLP) is quite different with no clear sign of precession and a different spatial structure (wave-3 rather than wave-2). At all observed times the anomaly precession in sea ice edge is almost entirely confined to the region $180^{\circ}$ to $0^{\circ} \mathrm{W}$. This long-term variation is compatible with the results of Murphy et al. [1995]. Murphy et al.'s [1995, Figure 2], showing fast ice duration at Signy Island, shows (by eye) 4 year periodicity after about 1985, 8 year periodicity between 1965 and 1985, and unclear periodicity, if present, for the previous 70 years. In section 3.3 we quantify these values by reanalyzing this record using wavelets.

[5] A further characteristic of the change in mode is a change in the predictability of MSLP from SST forcing. Rowell [1998] and Bengtsson et al. [1996] have shown that in the polar regions, there is little direct forcing of atmos- 

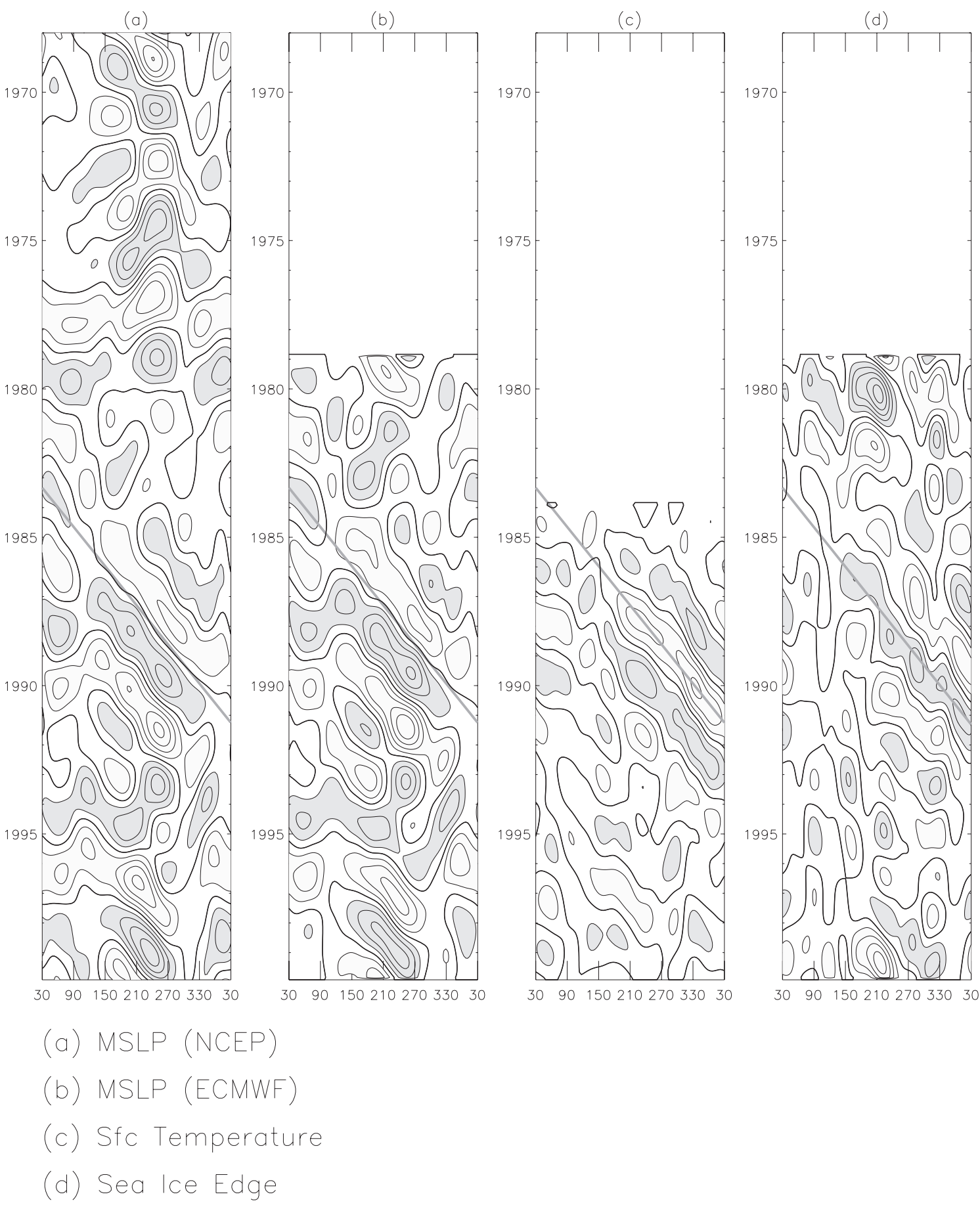

Figure 2. Hovmöller diagrams of data as in Figure 1, filtered between 3 and 7 years. The horizontal axis is drawn from $30^{\circ} \mathrm{E}$ clockwise for compatibility with WP. The shaded slanting line has a slope of $360^{\circ}$ in 8 years. The contour intervals are (a) $1 \mathrm{hPa}$ for NCEP MSLP, (b) $1 \mathrm{hPa}$ for ECMWF MSLP, (c) $1 / 2^{\circ} \mathrm{C}$ for ECMWF SST, and (d) $1 / 4^{\circ}$ latitude for SIE. The zero contour is drawn bold; each quantity is lightly/ heavily shaded above/below the first contour.

pheric anomalies from the surface. Connolley [1997] provides evidence for this in the Antarctic region. Evidence from GCM integration suggests that during the precessional mode of the ACW, there is enhanced predictability (as would be required to support a coupled ocean-atmosphere interaction). The studies mentioned above could not find this because they looked at an extended time period.
[6] White and Cayan [2000] show what they call a "Global ENSO Wave," which includes standing and propagating wave components; their analysis from 1900 to 1993 at $20^{\circ} \mathrm{N}$ [White and Cayan, 2000, Figure 6] shows decadal variations in the strength of this wave and the direction of its propagation. The connection between this and the $\mathrm{ACW}$ is not clear; nonetheless, it is suggestive that their analysis 

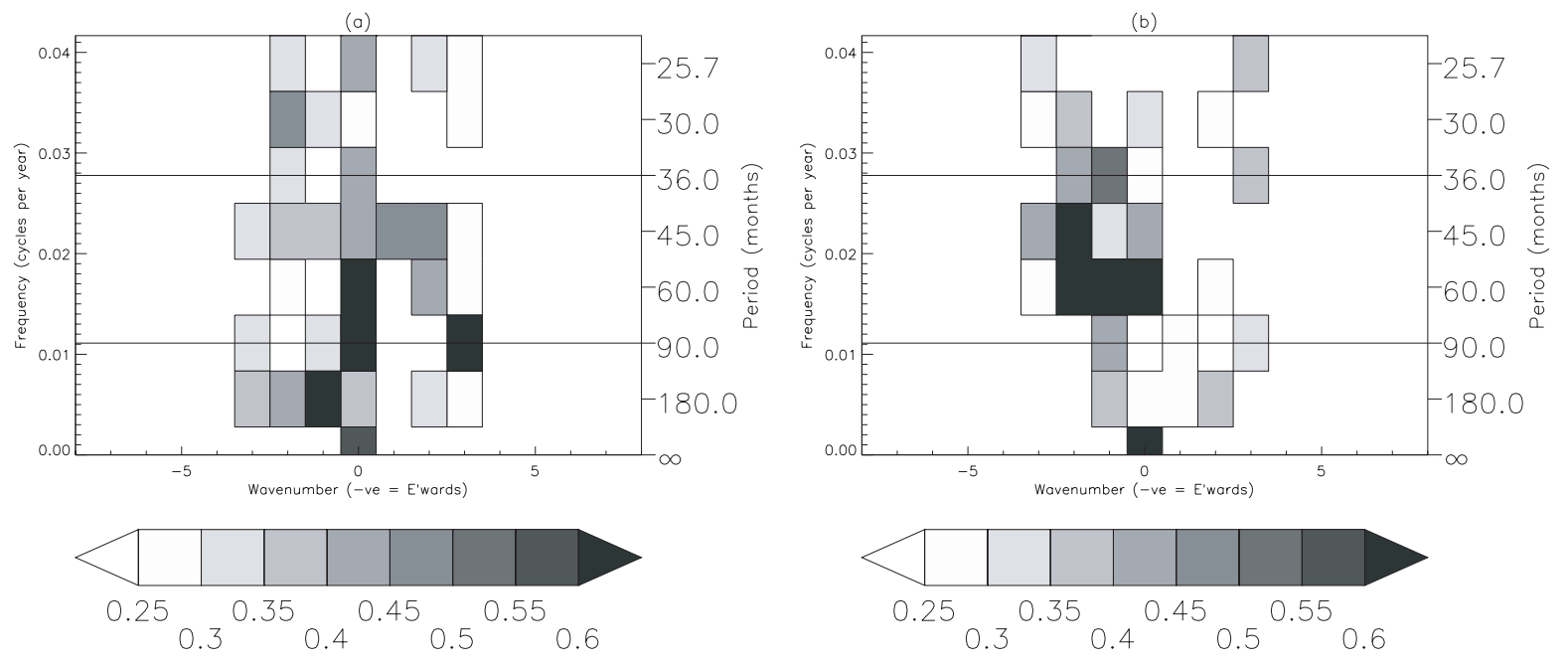

(a) MSLP NCEP (early; 1968-1982)

(b) MSLP NCEP (late; 1985-1999)

Figure 3. Amplitude of wave number-frequency spectra $(\mathrm{hPa})$ of Hovmöller plots of anomalies along $56^{\circ} \mathrm{S}$ in NCEP MSLP (a) for 1968-1982 and (b) for 1985-1999.

shows eastward propagation from 1982 to 1990, approximately the period found by this work to have a clear ACW signal, and weak or westward propagation after 1990 and from 1976 to 1981 . This points toward possible interactions with the tropics as a source for decadal variations in the ACW.

\section{Data}

[7] MSLP and surface temperature fields for the period 1979-1993 are taken from the ECMWF Re-Analyses (ERA) data set [Gibson et al., 1997] and extended to 1999 from the ECMWF operational analyses; this combined data set will be called "ECMWF." A longer-term MSLP data set starting in 1968 is taken from the NCEP reanalysis [Kalnay et al., 1996]. SSTs before 1983 are not well known in high southern latitudes and are input into the NCEP analysis from the Comprehensive Ocean-Atmosphere Data Set [Oberhuber, 1988]. Although the SSTs before 1983 are not well enough known to be worth analysis, MSLP fields are better constrained by observations: undoubtedly, the quality improves after 1979 when sea ice data and TIROS Operational Vertical Sounder (TOVS) soundings become available and after 1982 when satellite SSTs become available. Uppala [1997, Figure 195] shows the number and impact of drifting buoy observations upon the ERA reanalysis. The impact of the buoys, and the (good) fit to the analysis, stays quite constant from 1979 to 1993, even though the number between 40 and $60^{\circ} \mathrm{S}$ drops between 1980 and 1984, giving further confidence in the MSLP analysis. Before 1968, because of a lack of observations and problems inputting the available observations, the NCEP reanalyses are not reliable in high southern latitudes, but between 1968 and 1979 the analyses are believed to be acceptable [Marshall and Harangozo, 2000] for large-scale fields such as MSLP. Sea ice data for 1979-1999 comes from the Ocean Modeling Branch of the U.S. Environ- mental Modeling Center from the Special Sensor Microwave Imager (SSMI) instrument using the NASA Team algorithm [Grumbine, 1997].

[8] MSLP data from a set of GCM runs forced by observed SSTs and sea ice were obtained from the UK Meteorological Office Hadley Centre. These runs (called together "Climate of the 20th Century" or C20C) are described by Rowell [1998], and the six members of the ensemble are used here. These runs have been performed for the period 1949-1992; in order to be sure that the SSTs that they are forced by are reliable near Antarctica, only the data from 1979 onward are used.

[9] MSLP data for Kerguelen $\left(49.3^{\circ} \mathrm{S}, 70.2^{\circ} \mathrm{E}\right)$, Macquarie $\left(54.5^{\circ} \mathrm{S}, 159^{\circ} \mathrm{E}\right)$, and Signy $\left(60.7^{\circ} \mathrm{S}, 45.6^{\circ} \mathrm{W}\right)$ Islands are taken from Jones and Limbert [1987] and updated at the British Antarctic Survey, as is the near-surface temperature for Signy. Fast ice duration at Signy Island comes from Murphy et al. [1995].

\section{Analysis}

[10] Figure 1 shows (following WP) a wave numberfrequency decomposition of Hovmöller plots of MSLP and SST anomalies along $56^{\circ} \mathrm{S}$ and SIE anomalies. Although $56^{\circ} \mathrm{S}$ has been used here, the results of this study have been replicated using latitudes from $50^{\circ}$ to $60^{\circ} \mathrm{S}$. Most (but not all) power is in stationary and eastward propagating modes. Figure 2 shows the Hovmöller plots filtered to exclude periods outside the range 3-7 years and wave numbers $>8$. (Figure 1 shows that there is little power at wave numbers $>4$ and (although this is not shown) there is even less at wave numbers $>8$.) The range $3-7$ years was chosen by WP to include the most important interannual variations, which is confirmed by WP (Figure 1) and Figure 1 of this paper. For convenience the data were deseasonalized before filtering, but the filtering would have removed any annual periodicity present. MSLP fields are spatially smooth, and 
(a)

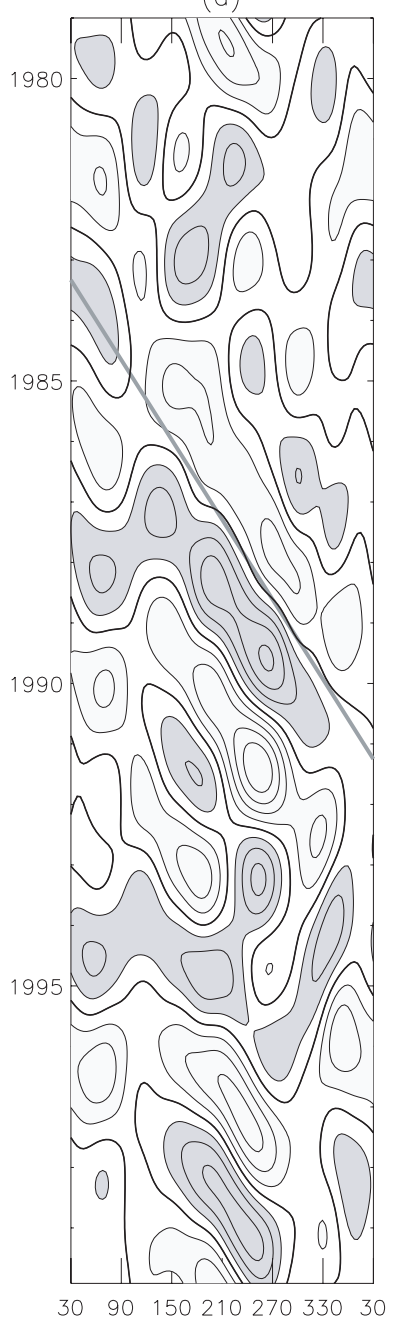

(b)

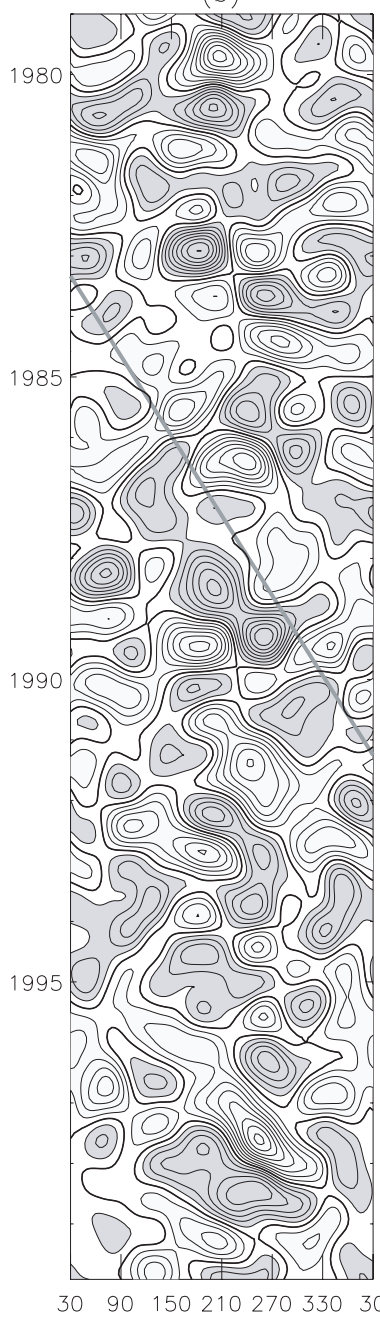

(c)

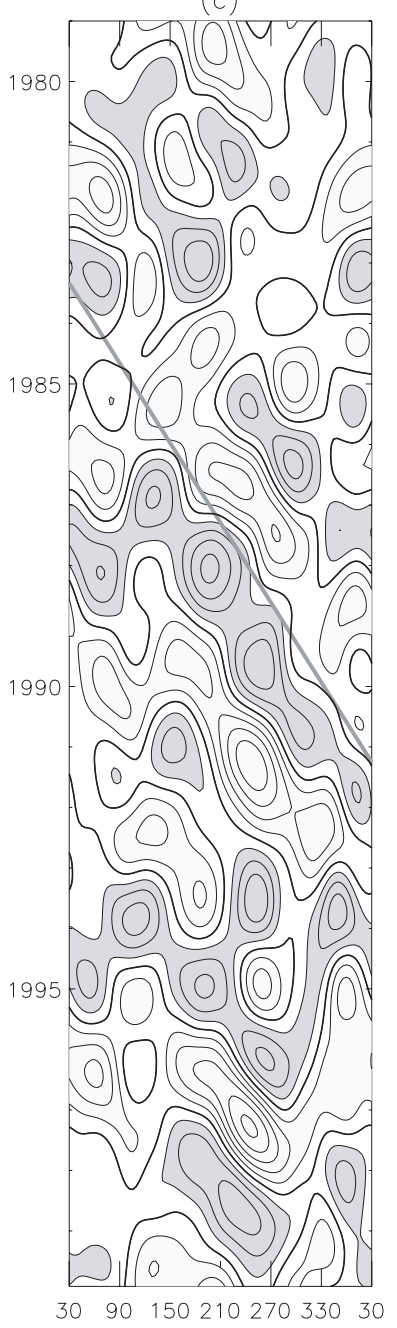

(d)

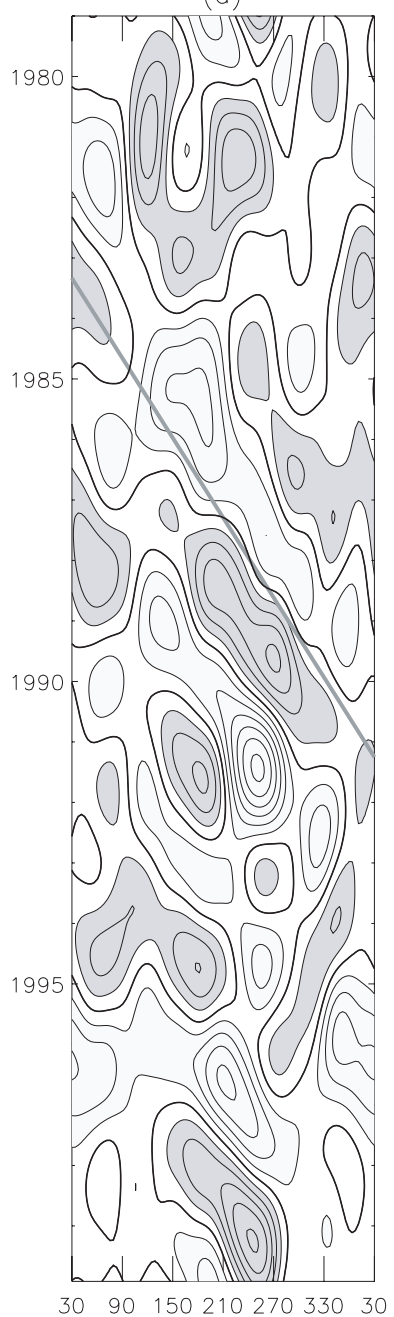

(a) MSLP (ERA) $3-7.5$
(b) MSLP (ERA) $1-7.5$
(c) MSLP (ERA) $2-7.5$
(d) MSLP (ERA) 3-infinity

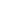




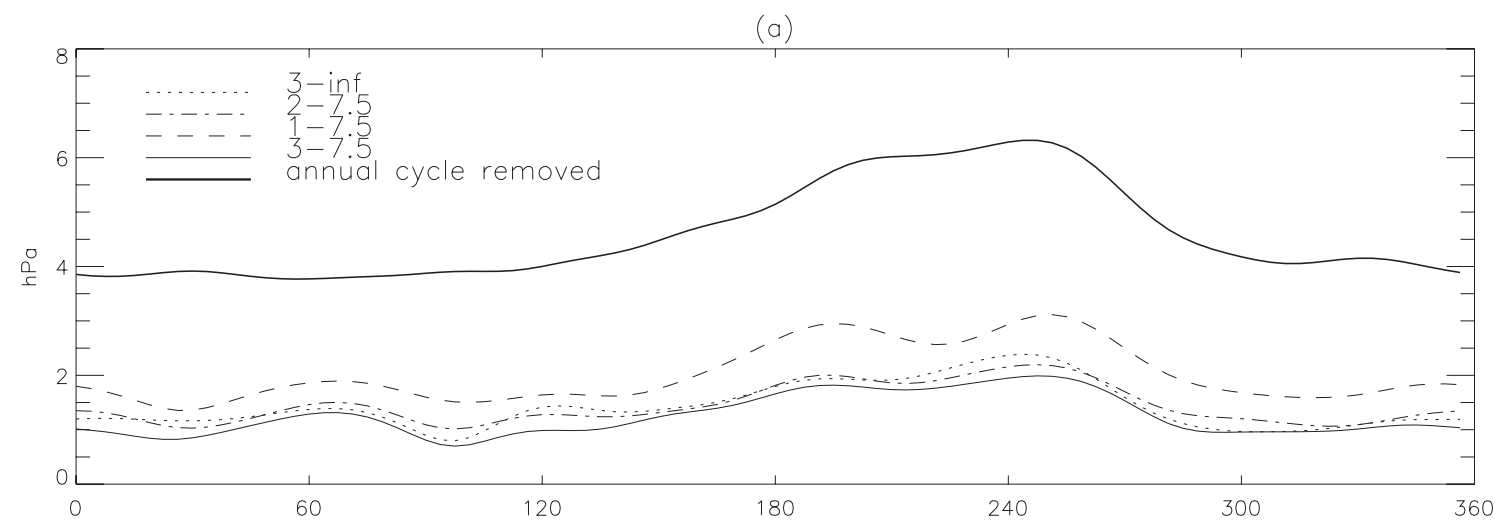

(b)
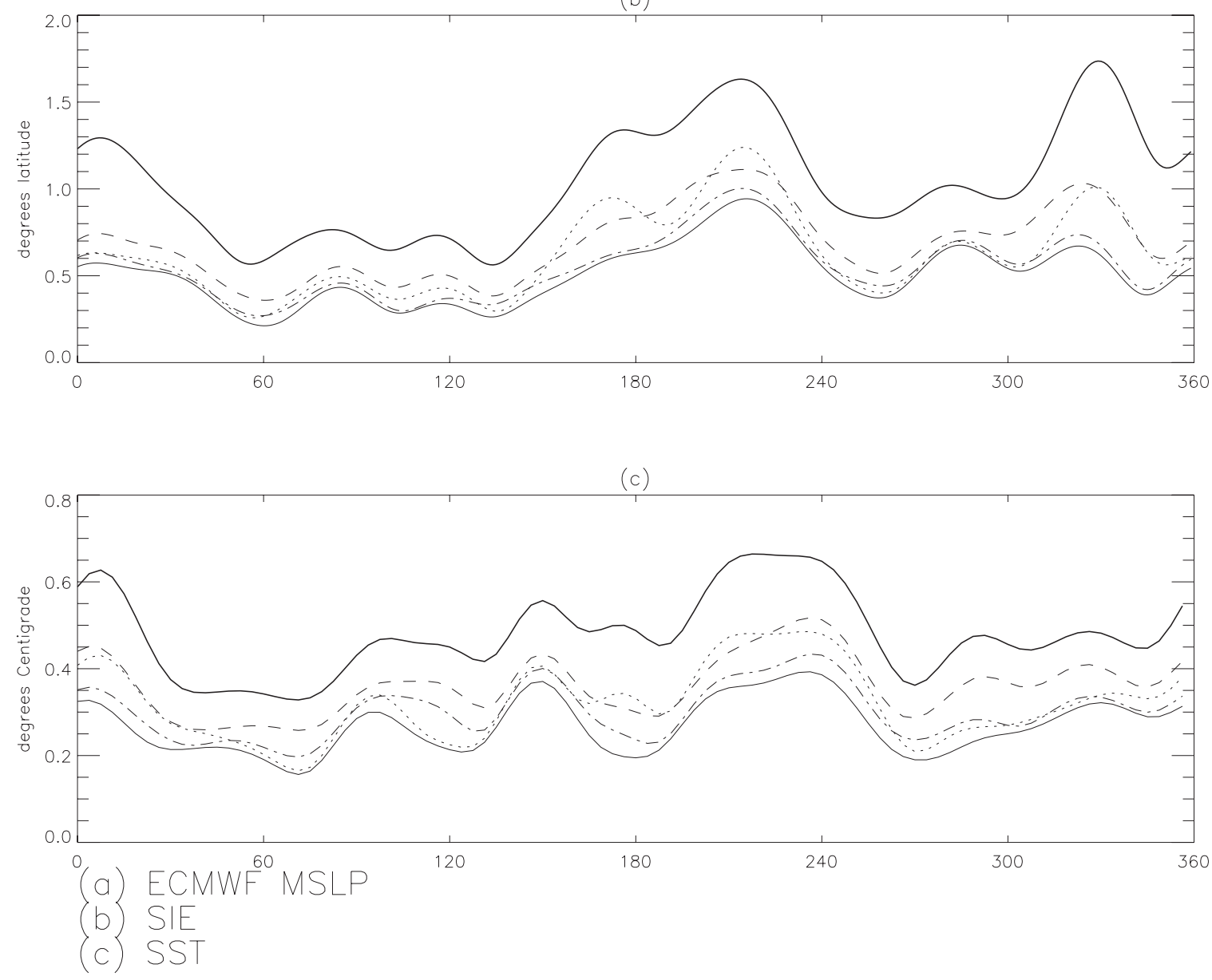

Figure 5. Standard deviation, by longitude, of (a) ECMWF MSLP, (b) SIE, and (c) SST. For the thick solid line, only the annual cycle is removed. Periods retained are solid line, 3-7 years; dotted line, above 3 years; dashed line, 1-7 years; and dot-dashed line, 2-7 years.

the signature is weak or nonexistent. Traces of eastward propagating anomalies are generally present, but except for the period 1985-1994 it is not clear that these anomalies form a well-defined wave structure. This conclusion was also reached by Bonekamp et al. [1999] using just the ECMWF data; however, it is less clear in their analysis (Bonekamp et al., Figure 1). Before the episode marked with the shaded line the signs of anomaly propagation are weak and broken, and in the early portion of the NCEP MSLP (Figure 2a), there is little sign of propagation at all. Between 1968 and 1980 the clearest signal in the NCEP MSLP is an $\sim 4$ year standing oscillation at about $120^{\circ} \mathrm{W}$. For SST, anomalies are strongest between $180^{\circ} \mathrm{W}$ and $0^{\circ} \mathrm{E}$. This is clearer in the SIE field (Figure 2d) where anomalies are very weak between $30^{\circ} \mathrm{W}$ and $180^{\circ} \mathrm{E}$, especially during the period (1985-1993) when the ACW is clearest in the SST data. 

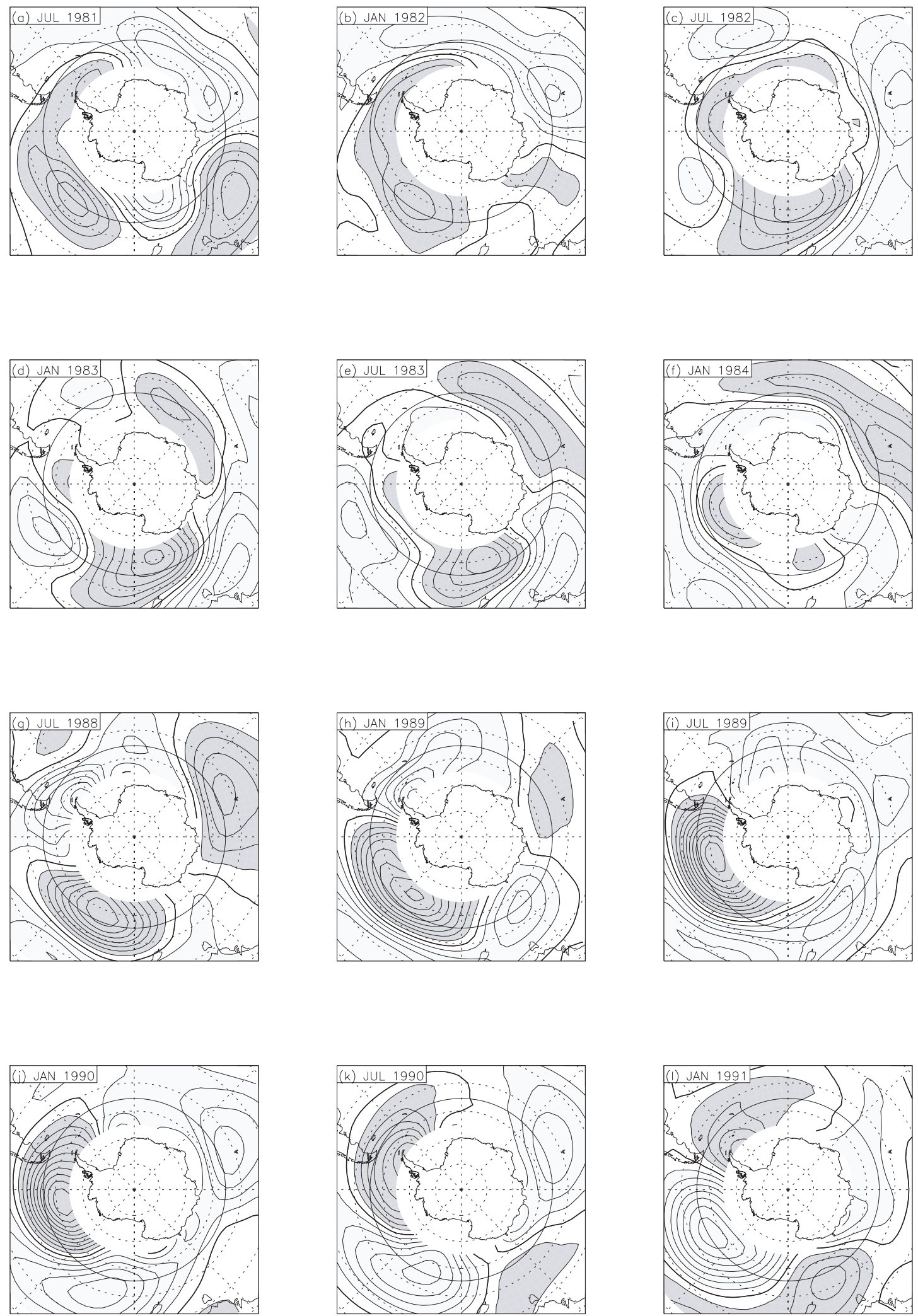

Figure 6. MSLP patterns filtered to periods between 3 and 7 years and wave numbers $\leq 8$, by latitude circle. The $56^{\circ} \mathrm{S}$ latitude circle is drawn. The contour interval $0.5 \mathrm{is} \mathrm{hPa}$; contours above/below $\pm 0.5 \mathrm{hPa}$ are lightly/heavily shaded. 

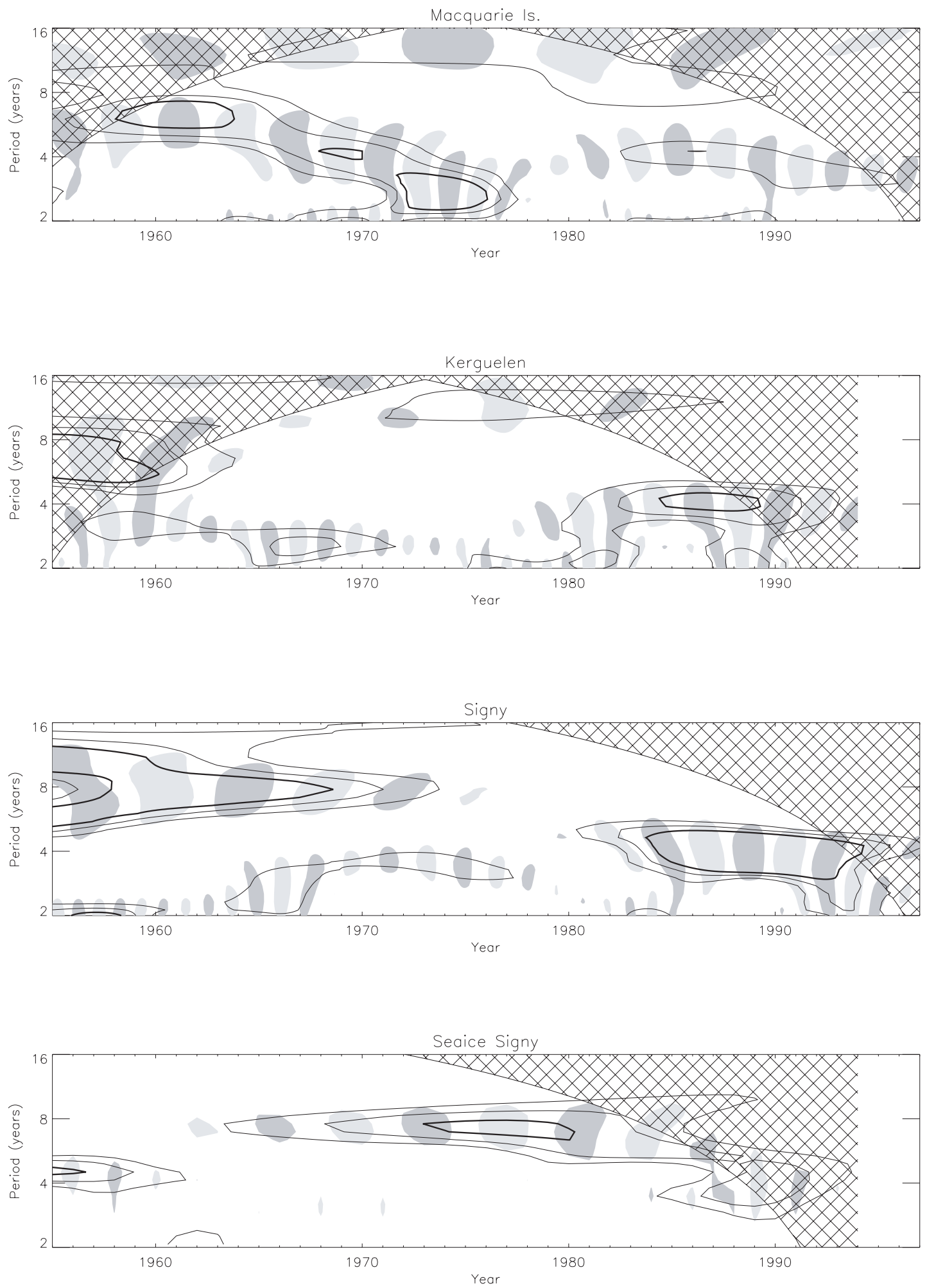

Figure 7. Wavelet decomposition of MSLP from (a) Macquarie Island $\left(54.5^{\circ} \mathrm{S}, 159.0^{\circ} \mathrm{E}\right)$, (b) Kerguelen $\left(49.2^{\circ} \mathrm{S}, 70.1^{\circ} \mathrm{E}\right)$, and (c) Signy $\left(60.7^{\circ} \mathrm{S}, 45.6^{\circ} \mathrm{W}\right)$ and (d) fast ice duration at Signy. Data are normalized by their respective standard deviations before the decomposition. The real part of the wavelet is shaded; contours of significance above the background spectrum [Torrence and Compo, 1998] are drawn at 80, 90, and (thicker) 95\% levels. 


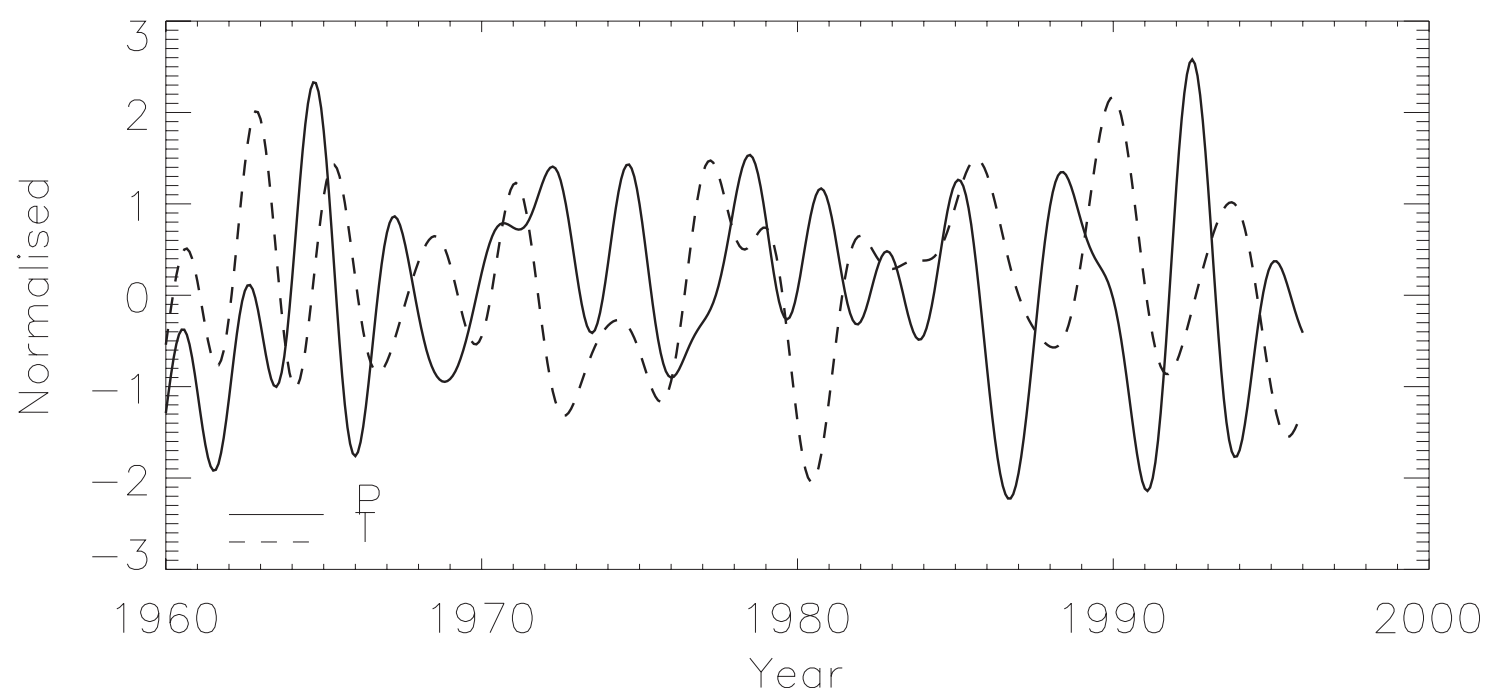

Figure 8. Normalized MSLP (solid) and near-surface (dashed) temperature from Signy, filtered to remove periods $<2$ years.

[13] The differences in spectra seen in Figures $1 \mathrm{a}$ and $1 \mathrm{~b}$ between ECMWF and NCEP MSLP are largely due to the differing time periods covered since in the early part of the NCEP record the signal is quite different. Figure 3 shows spectra for the 15 year periods at the start and end of the NCEP MSLP series. Figure 3a shows some power at ACWlike wave number/frequency, but other signals dominate, as would be expected from Figure $2 \mathrm{a}$. In contrast, in the latter half (1985-1999), there is a strong wave-2 signal with frequency of roughly 4 years.

\subsection{Dependence on Filtering Period}

[14] The main signal seen in Figure 2 is a wave- 2 period 4 year signal, which has been brought out by filtering between 3 and 7 years. Figure 4 shows the effect of different filtering periods on ECMWF MSLP. The filtering process removes a considerable amount of variance (compare Figures $4 \mathrm{a}$ and 4b) by removing periods between 1 and 3 years, although a comparison of Figures $4 \mathrm{~b}$ and $4 \mathrm{c}$ shows that most of this loss occurs at periods of between 1 and 2 years (note that the annual cycle has already been removed), whereas Figure $4 \mathrm{~d}$ shows that there is little change if there is no low cutoff in the filtering.

[15] Figure 5 shows the standard deviation of ECMWF MSLP, SST, and SIE by longitude. For MSLP this confirms the impression from Figure 2 that highest variance occurs between $180^{\circ}$ and $300^{\circ} \mathrm{W}$ but also shows how much is lost by filtering: $\sim 30 \%$ remains when $3-7$ year filtering is applied (note that the annual cycle has been removed from all data sets). The broad peak in variability found between $180^{\circ}$ and $300^{\circ} \mathrm{W}$ coincides with the "West Antarctic Pole of Variability" [Connolley, 1997]. SST and SIE show less reduction in variability than MSLP (only about $50 \%$ is lost, quite uniformly in longitude), and this is consistent with the longer memory of the ocean. The SIE shows low variability between $60^{\circ}$ and $120^{\circ} \mathrm{E}$ and peaks in variability at the longitudes of the Ross and Weddell Seas.

\subsection{Spatial Patterns of Variation}

[16] In Figure 6 the MSLP has been filtered to retain 3-7 year periodicity, and maps are drawn at 6 month intervals during the period when the ACW appears (Figures 6g-61) and in the early period (Figures $6 \mathrm{a}-6 \mathrm{f}$ ). The data are excluded south of $65^{\circ} \mathrm{S}$ to prevent contamination of the MSLP field by the high orography. The character of the spatial variability changes over time: before 1985 , there is a wave-3 pattern, if anything; after 1985 the data show the wave-2 pattern shown by White et al. [1998]. In the early period, there is no clear sign of precession of the anomalies, and the anomaly pattern flips between positive and negative phases (Figures 6a-6f). During the period (1985-1994) when the ACW appears clearest in Figure 2, there is a different structure of wave-2, which precesses at $\sim 360^{\circ}$ in 8 years (Figures $6 g-61$ ). The anomalies are largest in the southwest Pacific sector, grow as they enter this region, and decay as they leave it: this was noted by Christoph et al. [1998]. The split into two modes is shown by Connolley [1997, Figure 3] where the standard deviation of the climatological MSLP field is shown to have a wave-3 structure when data from 1973 onward are used, but from 1984 to 1993 the pattern is dominated by a dipole between the Amundsen-Bellingshausen Seas and south of New Zealand.

\subsection{Wavelet and Phase Analysis of Long-Term Station Records}

[17] To study the variation of the ACW, it is desirable to use a long-term record; unfortunately, the earliest NCEP analyses are unreliable in this region, and even after 1968, the quality is not as good as in the satellite era, after 1979. However, there are a few long-term records from individual stations that can be examined for longer-term variations. Longitudinal propagation cannot be seen because of the geographic sparseness of the stations, but one may examine the variability for ACW-like periodicity. Since I am particularly interested in time-varying signals, wavelet analysis [Torrence and Compo, 1998] is used. Figure 7 shows a time-frequency decomposition of MSLP at (a) Macquarie, (b) Kerguelen, and (c) Signy Islands and (d) fast ice duration at Signy Island. The latitudes of these stations are within the region generally considered to be influenced 

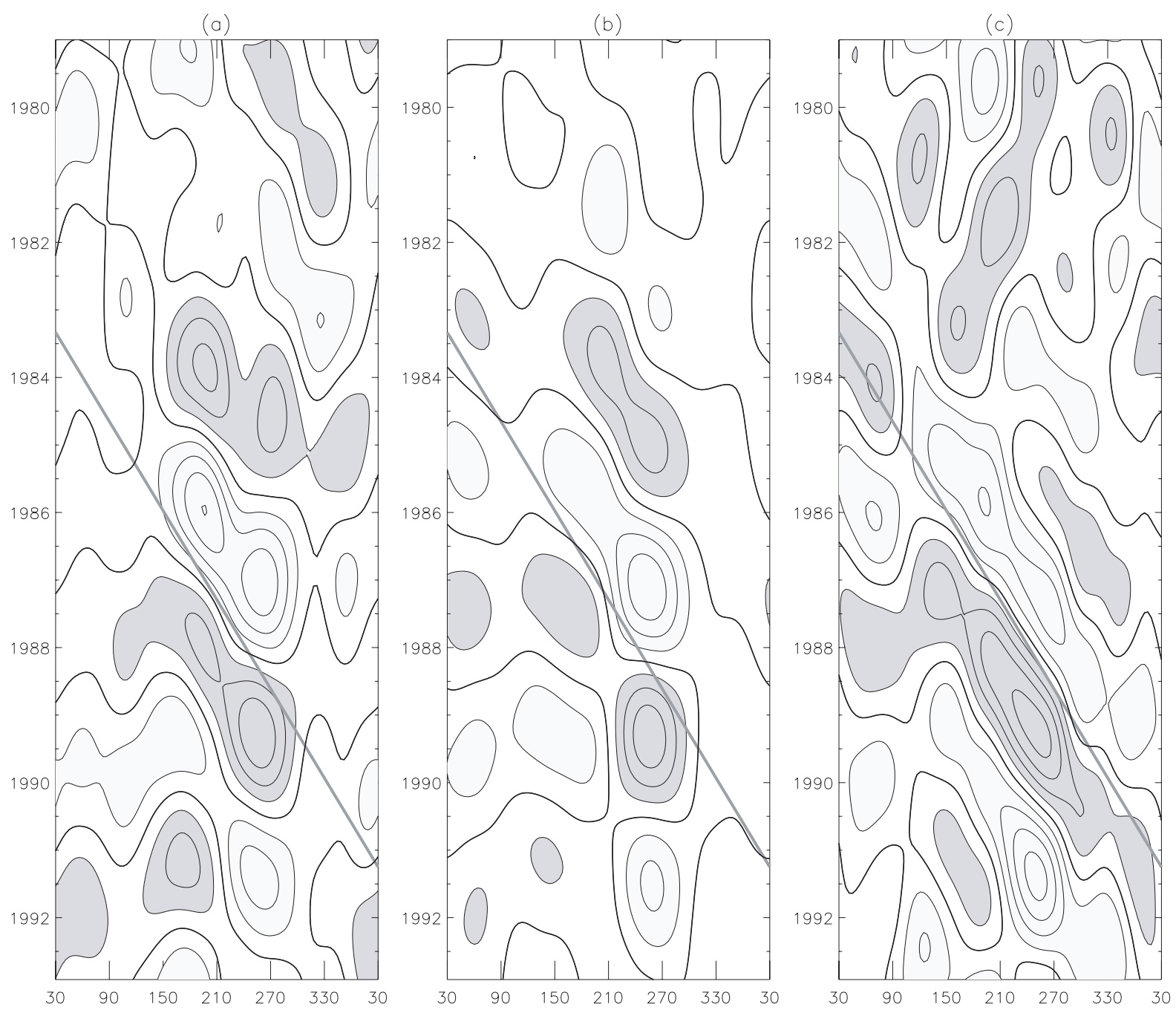
(a) MSLP (C20C, member 1)
(b) MSLP (C20C, ensemble average)
(c) MSLP (ECMWF)

Figure 9. Hovmöller diagrams of MSLP, filtered to retain between 3 and 7 years, for 1979-1992: (a) C20C member 1, (b) C20C ensemble average, (c) and ECMWF. The contour interval is $1 \mathrm{hPa}$.

by the ACW $\left(40^{\circ}-60^{\circ} \mathrm{S}\right)$. The raw Signy sea ice data have a significant trend that has been removed prior to this analysis, but (as expected) this makes little difference to the analysis. Data are normalized by their standard deviation prior to decomposition. Cross-hatched areas on Figure 7 indicate regions where the variance is reduced by edge effects from zero padding, and these regions are less reliable [Torrence and Compo, 1998]. I have chosen to focus on the period after 1960, which removes this problem at the beginning of the records.

[18] In all cases in Figure 7, 4 year periodicity, compatible with an ACW signature, dominates between approximately 1985 and 1994, the period used by WP. Around 1980 this 4 year signal vanishes, and before 1980 the results are different at the different stations, with both longer-term (generally around 8 year) and shorter-term $(2-3$ year) periodicity. The strong 8 year signal in the sea ice record from Signy (7 days) is consistent with the interpretation of Murphy et al. [1995].

[19] The results of White and Cayan [2000] provide a possible mechanism for decadal modulation of the ACW and are consistent with the lack of ACW seen prior to 1982 in Figure 2. If this link is taken literally, White and Cayan [2000, Figure 6] would indicate a return to ACW-like conditions between 1964 and 1976. This is perhaps partly visible in Figure 2a and is consistent with wavelet analysis of the MSLP record from Macquarie Island (Figure 7a) and Signy (Figure 7c), although not with Figure $7 \mathrm{~b}$ or $7 \mathrm{~d}$.

[20] A characteristic feature of the ACW is that MSLP anomalies precede temperature anomalies by $\sim 1$ year 


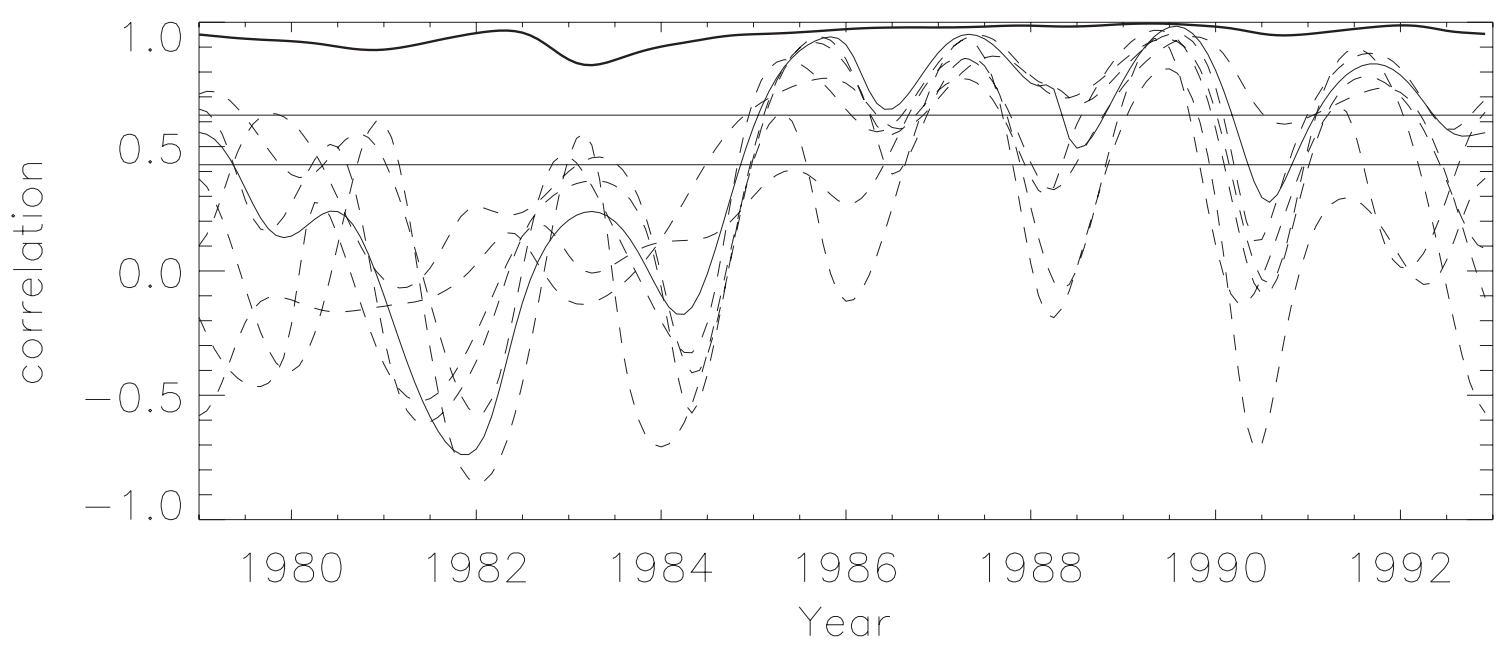

Dashed: ensemble members against ECMWF

Solid: ensemble avg

Thick line: ECMWF VS NCEP

Figure 10. Correlation between 3 and 7 year filtered MSLP anomalies at $56^{\circ} \mathrm{S}$ : ECMWF against NCEP (thick line) and C20C against ECMWF (dashed thin lines: ensemble members; solid line: ensemble average). Horizontal lines are $95 \%$ significance values for correlations with 8 and 16 degrees of freedom.

(WP). Temperature anomalies from an island station may be considered representative of the surrounding seas. Figure 8 shows time series of MSLP and near-surface temperature at Signy low-pass filtered to remove periods shorter than 2 years and then normalized by standard deviation. After 1985 the phase lag between temperature and pressure is 1 year, with pressure leading temperature, with a 4 year period. Just after 1960, temperature and pressure are in phase, with a 2 year period. In between, the phase relationship is variable. This provides further evidence that the ACW was not present during this early period.

\subsection{Connection to Potential Predictability}

[21] Previous studies [e.g., Rowell, 1998] have indicated that the potential predictability of atmospheric fields in the south polar region is low. This is apparently contradicted by the appearance of a coupled ocean-atmosphere mode. However, limited predictability does appear in certain seasons (June, July, and August and September, October, and November). Interestingly, Zwiers and Kharin [1998] show a local maximum in predictability in the AmundsenBellingshausen Seas region in December, January, and February, which corresponds to the region of greatest MSLP variability.

[22] To help assess the role of the ocean in forcing the atmospheric anomalies, we examine the behavior of the ensemble used by Rowell [1998]. Figure 9 shows Hovmöller plots for one member of the C20C ensemble and for the ensemble average for the period 1979-1992 and the ECMWF data for the same period for reference. Although there are differences, it appears that the $\mathrm{C} 20 \mathrm{C}$ runs have captured a large part of the time-filtered anomalies in MSLP, particularly for the period 1985 onward. This is confirmed by considering the spatial correlation along $56^{\circ} \mathrm{S}$ between the anomalies. Figure 10 shows that after 1985 the correlations between the ensemble members and ECMWF, although oscillating with an $\sim 2$ year period, peaked at significant values. Figure 10 shows 95\% significance values for correlations with 8 and 16 degrees of freedom: the correlations have 16 degrees of freedom, since eight waves are retained; however, Figure 1 shows that in practice most variance is contained within the first four waves; hence both estimates are shown. Figure 10 shows that the ECMWF correlations with NCEP are very high. This reflects the quality of both analyses and their constraint by observations, but the correlations do appear to be even higher after 1985. This is consistent with the better correlations between $\mathrm{C} 20 \mathrm{C}$ and observations in this period and suggests that the atmospheric anomalies were more directly forced by oceanic anomalies in this latter period.

[23] The regular falls away from high correlation between ECMWF and C20C, seen in Figure 10, can be explained by Figure 9. This shows that whereas the ECMWF data indicates a smooth anomaly precession (e.g., the negative anomaly just after the shaded reference line in Figure 9 or the positive anomaly following it), the C20C integrations show a transition between anomaly centers. This was also the case with the coupled AOGCM results of Christoph et al. [1998]. The falls away from correlation in the C20C are regular and reproducible between ensemble members. This may be because the atmosphere is inherently less predictable during certain periods in the precessing phase of the ACW. Alternatively, it may be caused by flaws in the GCM used: the Antarctic circumpolar trough is known to be too deep in the UK Meteorological Office model used here [Connolley and Cattle, 1994].

[24] A further important feature of Figure 10 is that from 1985 onward, when correlations are significant, the correlation of the ensemble average against ECMWF is in general higher than any of the members. Before 1985 the ensemble average is no better or worse than the members. If 
the ensemble members are reproducing the true signal plus noise, then the ensemble average, by averaging the noise, will produce a better approximation to the signal, and this is what appears, from 1985 onward.

\section{Conclusion}

[25] The results presented here suggest that the oceanatmosphere anomalies around Antarctica exist in two modes, one (that reported by WP and confirmed by other authors) characterized by a wave number of two and a 4 year period at any location and one showing little propagation and a wave number of three. The gridded data sets currently available are too short to allow us to say how much time is spent in each mode (or other modes entirely), though the station observations of section 3.3 and the results of Murphy et al. [1995] suggest that the wave-2 structure is quite infrequent. The existence of the nonpropagating mode, characterized by standing oscillations, is somewhat supported by some GCM modeling studies [Christoph et al., 1998; Cai et al., 1999], which found propagating SST anomalies interacting with a generally stationary MSLP variation. The recent theoretical study of White et al. [1998] would appear to show that the "classic" ACW pattern should always be present; however, the observational study of White and Cayan [2000] provides a possible mechanism for decadal variation by interaction with a Global ENSO Wave.

[26] The comparison with GCM integrations forced by observed SSTs and sea ice reveals that a significant component of atmospheric variability is forced by SST variations, although this only becomes apparent in the smoothed data and is only valid during the precessional phase of the ACW. Bonekamp et al. [1999] and Weisse et al. [1999] have shown that stochastic atmospheric forcing can generate an oceanic response resembling the ACW, although the timescales (and possibly space scales) generated were different from those observed, possibly because of limitations of the ocean model. They used this to argue that the observed ACW can be largely explained as oceanic advection of the response to these atmospheric anomalies. The $\mathrm{C} 20 \mathrm{C}$ results show that at least during the precessional ACW phase, oceanic forcing can generate precessing anomalies in the atmosphere and thus support WP in that the ACW is a true coupled mode of the ocean-atmosphere system.

[27] Acknowledgments. I am grateful to J. C. King for fruitful discussions, the British Atmospheric Data Centre for supplying the ECMWF data, and D. Rowell, C. Folland, A. Renshaw, D. Sexton, and J. Davies (DoE contract PECD3/12/37 and CEC contract EV5V-CT920121) for $\mathrm{C} 20 \mathrm{C}$ model results. Wavelet software was provided by C. Torrence and G. Compo and is available at URL:http://paos.colorado.edu/ research/wavelets/. Comments by two anonymous referees improved the paper.

\section{References}

Bengtsson, L., K. Arpe, E. Roeckner, and U. Schulzweida, Climate predictability experiments with a general circulation model, Clim. Dyn., 12, 261-278, 1996.

Bonekamp, H., A. Sterl, and G. J. Komen, Interannual variability in the Southern Ocean from an ocean model forced by European Centre for Medium-Range Weather Forecasts reanalysis fluxes, J. Geophys. Res., 13,317-13,331, 1999.

Cai, W., P. G. Baines, and H. B. Gordon, Southern mid to high-latitude variability, a zonal wavenumber-3 pattern, and the Antarctic Circumpolar Wave in the CSIRO coupled model, J. Clim., 12, 3087-3104, 1999.

Christoph, M., T. P. Barnett, and E. Roeckner, The Antarctic Circumpolar Wave in a coupled ocean-atmosphere GCM, J. Clim., 11, 1659-1672, 1998.

Connolley, W. M., Variability in annual mean circulation in southern high latitudes, Clim. Dyn., 13, 745-756, 1997.

Connolley, W. M., and H. Cattle, The Antarctic climate of the UKMO unified model, Antarct. Sci., 6, 115-122, 1994.

Gibson, J. K., P. Kallberg, S. Uppala, A. Nomura, A. Hernandez, and E. Serrano, ERA description, ECMWF Reanal. Proj. Rep. Ser. 1, 72 pp., Eur. Cent. for Medium-Range Weather Forecasts, Reading, UK., 1997.

Grumbine, R. W., Automated ice concentration analysis, Tech. Proced. Bull. 440, Natl. Weather Serv., Silver Spring, Md., 1997.

Jacobs, G. A., and J. L. Mitchell, Ocean circulation variations associated with the Antarctic Circumpolar Wave, Geophys. Res. Lett., 2947-2950, 1996.

Jones, P. D., and D. W. S. Limbert, A data bank of Antarctic Surface temperature and pressure data, Rep. TR038, 52 pp., Off. of Energy Res., U.S. Dep. of Energy, Washington, D. C., 1987.

Kalnay, E., et al., The NCEP/NCAR 40-year reanalysis project, Bull. Am. Meteorol. Soc., 77, 437-472, 1996.

Marshall, G. J., and S. A. Harangozo, An appraisal of NCEP/NCAR reanalysis MSLP data viability for climate studies in the South Pacific, Geophys. Res. Lett., 2000.

Murphy, E. J., A. Clarke, C. Symon, and J. Priddle, Temporal variation in Antarctic sea-ice-Analysis of a long-term fast-ice record from the South-Orkney Islands, Deep Sea Res., Part I, 42, 1045-1062, 1995.

Oberhuber, J. M., An Atlas based on the COADS data set: The budgets of heat, buoyancy and turbulent kinetic energy at the surface of the global ocean, Rep. 15, Max-Planck-Inst. für Meteorol., Hamburg, Germany, 1988.

Qiu, B., and F. Jin, Antarctic Circumpolar Waves: An indication of oceanatmosphere coupling in the extratropics, Geophys. Res. Lett., 24, $2585-$ 2588, 1997.

Rowell, D. P., Assessing potential seasonal predictability with an ensemble of multidecadal GCM simulations, J. Clim., 11, 109-120, 1998.

Torrence, C., and G. P. Compo, A practical guide to wavelet analysis, Bull. Am. Meteorol. Soc., 79, 61-78, 1998.

Uppala, S., Observing system performance in ERA, ECMWF Reanal. Proj. Rep. Ser. 3, 261 pp., Eur. Cent. for Medium-Range Weather Forecasts, Reading, UK, 1997.

Weisse, R., U. Mikolajewicz, A. Sterl, and S. S. Drijfhout, Stochastically forced variability in the Antarctic Circumpolar Current, J. Geophys. Res., 104, 11,049-11,064, 1999.

White, W. B., and D. R. Cayan, A global El Nino-Southern Oscillation wave in surface temperature and pressure and its interdecadal modulation from 1900 to 1997, J. Geophys. Res., 105, 11,223-11,242, 2000.

White, W. B., and R. G. Peterson, An Antarctic Circumpolar Wave in surface pressure, wind, temperature and sea-ice extent, Nature, 380, 699-702, 1996 .

White, W. B., S.-C. Chen, and R. G. Peterson, The Antarctic Circumpolar Wave: A beta effect in ocean-atmosphere coupling over the Southern Ocean, J. Phys. Oceanogr., 28, 2345-2361, 1998.

Zwiers, F. W., and V. V. Kharin, Intercomparison of interannual variability and potential predictability: An AMIP diagnostic subproject, Clim. Dyn., $14,517-528,1998$

W. M. Connolley, British Antarctic Survey, High Cross, Madingley Road, Cambridge CB3 0ET, UK. (wmc@bas.ac.uk) 